\title{
A zebrafish model to study small-fiber neuropathy reveals a potential role for GDAP1
}

Citation for published version (APA):

Eijkenboom, I., Vanoevelen, J. M., Hoeijmakers, J. G. J., Wijnen, I., Gerards, M., Faber, C. G., \& Smeets, H. J. M. (2019). A zebrafish model to study small-fiber neuropathy reveals a potential role for GDAP1. Mitochondrion, 47, 273-281. https://doi.org/10.1016/j.mito.2019.01.002

Document status and date:

Published: 01/07/2019

DOI:

10.1016/j.mito.2019.01.002

Document Version:

Publisher's PDF, also known as Version of record

Document license:

Taverne

Please check the document version of this publication:

- A submitted manuscript is the version of the article upon submission and before peer-review. There can be important differences between the submitted version and the official published version of record.

People interested in the research are advised to contact the author for the final version of the publication, or visit the DOI to the publisher's website.

- The final author version and the galley proof are versions of the publication after peer review.

- The final published version features the final layout of the paper including the volume, issue and page numbers.

Link to publication

\footnotetext{
General rights rights.

- You may freely distribute the URL identifying the publication in the public portal. please follow below link for the End User Agreement:

www.umlib.nl/taverne-license

Take down policy

If you believe that this document breaches copyright please contact us at:

repository@maastrichtuniversity.nl

providing details and we will investigate your claim.
}

Copyright and moral rights for the publications made accessible in the public portal are retained by the authors and/or other copyright owners and it is a condition of accessing publications that users recognise and abide by the legal requirements associated with these

- Users may download and print one copy of any publication from the public portal for the purpose of private study or research.

- You may not further distribute the material or use it for any profit-making activity or commercial gain

If the publication is distributed under the terms of Article $25 \mathrm{fa}$ of the Dutch Copyright Act, indicated by the "Taverne" license above, 


\title{
A zebrafish model to study small-fiber neuropathy reveals a potential role for GDAP1
}

\author{
Ivo Eijkenboom $^{\mathrm{a}, \mathrm{b}}$, Jo M. Vanoevelen ${ }^{\mathrm{c}, \mathrm{d}}$, Janneke G.J. Hoeijmakers ${ }^{\mathrm{b}, \mathrm{e}}$, Iris Wijnen ${ }^{\mathrm{a}}$, Mike Gerards ${ }^{\mathrm{f}}$, \\ Catharina G. Faber ${ }^{\mathrm{b}, \mathrm{e}}$, Hubert J.M. Smeets ${ }^{\mathrm{a}, \mathrm{b}, *}$ \\ ${ }^{a}$ Department of Genetics and Cell Biology, Clinical Genomics Unit, Maastricht University, P.O. Box 616, 6200 MD, Maastricht, The Netherlands. \\ ${ }^{\mathrm{b}}$ MHeNs School for Mental Health and Neuroscience, Maastricht University, Maastricht, The Netherlands. \\ ${ }^{\mathrm{c}}$ Department of Clinical Genetics, Maastricht University Medical Center+, Maastricht, The Netherlands. \\ ${ }^{\mathrm{d}}$ GROW School for Oncology and Developmental Biology, Maastricht University, Maastricht, The Netherlands. \\ ${ }^{\mathrm{e}}$ Department of Neurology, Maastricht University Medical Center, Maastricht, The Netherlands. \\ ${ }^{\mathrm{f}}$ Maastricht Centre for Systems Biology (MaCSBio), Maastricht University, Maastricht, The Netherlands.
}

\section{A R T I C L E I N F O}

\section{Keywords:}

Zebrafish

Mitochondrial dynamics

Sensory neurites

Fusion

Fission

Small-fiber neuropathy

\begin{abstract}
A B S T R A C T
Mutations in genes involved in mitochondrial dynamics (fusion and fission) have been implicated in many peripheral neuropathies. We hypothesized that defects in these genes could result in a phenotype resembling features of small-fiber neuropathy (SFN). This was investigated in zebrafish by knocking down two genes involved in mitochondrial dynamics gdap1 (possibly fission and motility) and opa1 (fusion) using established morpholinos. Our read-outs were nerve density in the caudal fin and a behavioral response to temperature changes, both based on comparable hallmarks of SFN in patients. Knockdown of gdap1 resulted in zebrafish embryos with a reduced density of sensory neurites compared to control morpholino-injected embryos. Furthermore, these embryos demonstrated a decreased temperature-related activity. In contrast, a knockdown of opa1 did not affect the density of sensory neurites nor the temperature-related activity. However, only the opa1 morphants had an effect on mitochondrial network morphology. As we were not able to visualize the mitochondria in the neurons, it could well be that changes in the mitochondrial network remained undetected. Our data indicate that GDAP1 knockdown affects sensory neurite development, however, it is unclear if a problem in mitochondrial fission and network formation is the pathophysiological mechanism. Although we did not observe an effect of inhibiting mitochondrial fusion during development, we still propose that genes involved in mitochondrial dynamics should be screened for mutations in patients with SFN.
\end{abstract}

\section{Introduction}

Mitochondrial fusion and fission also referred to as mitochondrial dynamics, are in combination with mitochondrial transport key processes in regulating quality control, maintenance and distribution of mitochondria in cells (Ni et al., 2015). Mitochondrial fission results in mitochondrial division and thus the formation of new daughter mitochondria (Scott and Youle, 2010). Generating sufficient, small mitochondria is essential to repopulate daughter cells during cell division, but also to enable transport of mitochondria along the extensions of developing neurons (Chen and Chan, 2017; Ishihara et al., 2009). Fission serves also as part of the quality control system by separating damaged mitochondria that can be removed by mitophagy (Youle and Van Der Bliek, 2012). The counterpart of fission, mitochondrial fusion, leads to mitochondrial merging and allows the exchange of contents between mitochondria (Hoppins and Nunnari, 2009). Both processes respond to metabolic or environmental changes (Wai and Langer, 2016). Under normal conditions, a balance between these processes is necessary to keep a healthy population of mitochondria in cells. Mitochondrial dynamics and intracellular mitochondrial transport are important for the distribution of healthy mitochondria along axons. Since neuronal cells require large amounts of energy and are lengthy, they are particularly sensitive to deficiencies in these processes.

Mitochondrial fission and fusion are mechanistically complex, involving many proteins that are required for the separation and merging of mitochondria (Fig. 1) (Pareyson et al., 2015). The possible mitochondrial fission factor GDAP1 (ganglioside-induced differentiation associated protein-1) is a tail-anchored protein of the mitochondrial

\footnotetext{
*Corresponding author at: Department of Genetics and Cell Biology, Clinical Genomics Unit, Maastricht University, P.O. Box 616, 6200 MD Maastricht, The Netherlands.

E-mail address: bert.smeets@maastrichtuniversity.nl (H.J.M. Smeets).
} 


\section{Mitochondrial Fission}
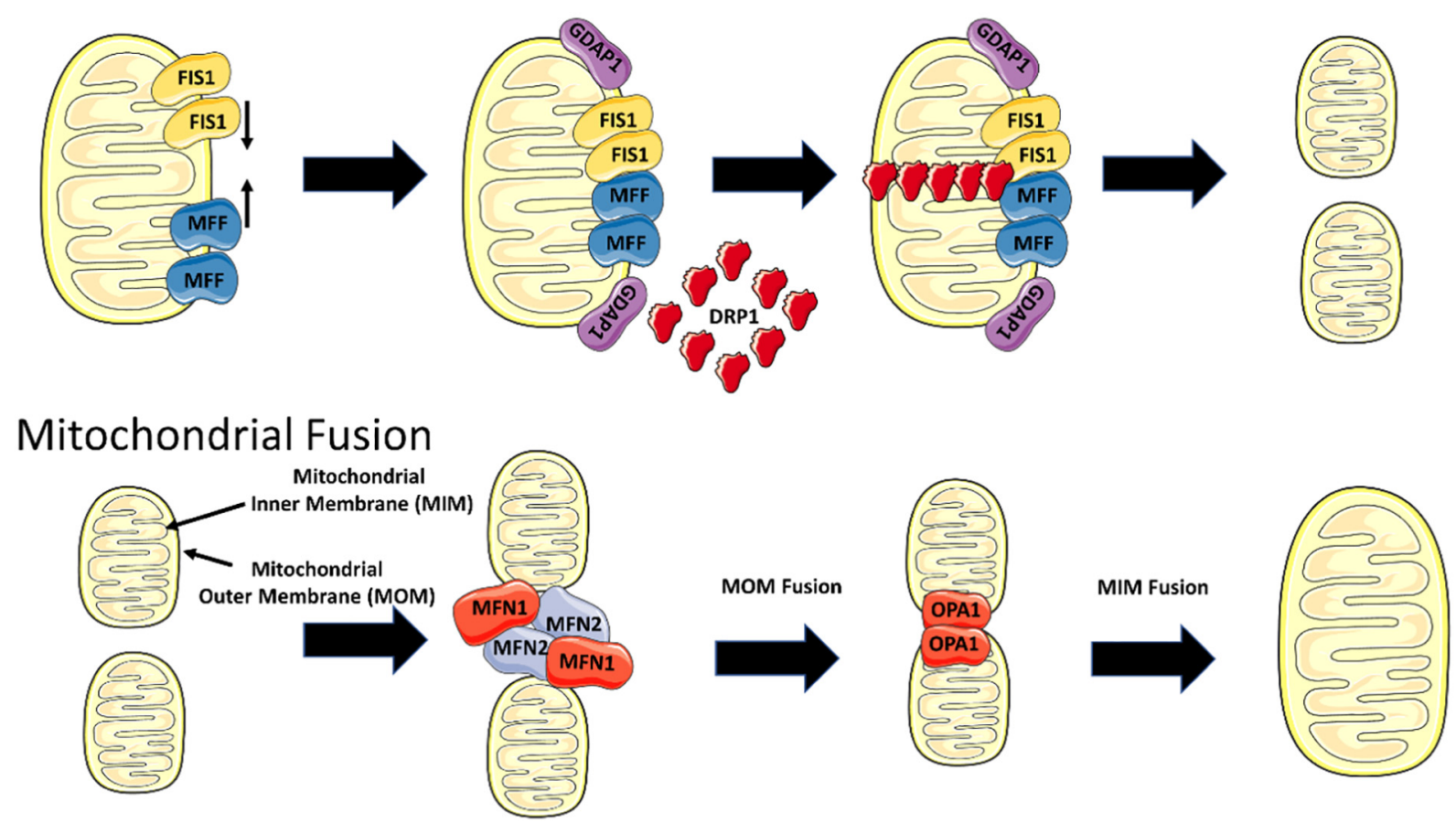

Fig. 1. Overview of mitochondrial fission (upper panel) and mitochondrial fusion (lower panel). Mitochondrial fission which takes place at the ER is mediated by FIS1, MFF, GDAP1 and the recruitment of DRP1. This will result in the formation of two daughter mitochondria. Mitochondrial fusion consists of fusion of the Mitochondrial Outer Membrane (MOM) mediated by MFN1 and MFN2 which is followed by fusion of the Mitochondrial Inner Membrane (MIM) mediated by OPA1 which interacts with MFN1. Adapted from: (Pareyson et al., 2015). \# Image designed with Servier Medical Art https://smart.servier.com/.

outer membrane (MOM) consisting of 358 amino acids (Niemann et al., 2005; Pedrola et al., 2005). GDAP1 plays a role in neuronal development, as it was upregulated during mouse brain development and it was highly expressed in the nervous system (Liu et al., 1999; Cuesta et al., 2002). A role in fission was proposed by Niemann et al. who demonstrated that GDAP1 overexpression resulted in mitochondrial network fragmentation, while mitochondria were elongated in knockdown experiments (Niemann et al., 2005). In contrast, Pla-Martín et al. did not observe an increase in mitochondrial tubulation in a gdap1 knock-down human neuroblastoma cell line. They reported an increase of mitochondria, however, with normal elongation indexes and a decrease of mitochondrial interconnectivity (Pla-Martin et al., 2013). Furthermore, a zebrafish model with a knockdown of gdap1 revealed an important function in peripheral motor neuron axon branching, extension, and pathfinding in the developing embryo (Gonzaga-Jauregui et al., 2015). These data indicated a critical role for GDAP1 during neuronal development, but no definite evidence for a role in mitochondrial fission.

Mitochondrial fusion involves both the mitochondrial outer membrane (MOM) and the mitochondrial Inner Membrane (MIM). A key player in fusion of the MIM is OPA1, which contributes to cristae modeling (Pernas and Scorrano, 2016). OPA1 knockdown in HeLa cells severely affected mitochondrial functioning by disrupting the mitochondrial network, disorganizing the cristae (Olichon et al., 2003), followed by caspase-dependent apoptosis and cytochrome $\mathrm{C}$ release (Olichon et al., 2003). OPA1 is necessary for mitochondrial metabolism in zebrafish and OPA1 knockdown affected the early development of zebrafish embryos. These morphants displayed a variety of phenotypical aspects including a reduced touch response (Rahn et al., 2013), indicating that OPA1 knockdown could potentially affect sensory neurite development as well.

Mutations in genes involved in mitochondrial dynamics (fusion and fission) have been implicated in many neurodegenerative disorders and peripheral neuropathies including, Charcot-Marie-Tooth disease (CMT), early-onset and progressive dominant optic atrophy, hereditary sensory and autonomic neuropathy (Zuchner et al., 2004; Kijima et al., 2005; Cuesta et al., 2002; Bertholet et al., 2016; Pareyson et al., 2015; Chen and Chan, 2009; Abrams et al., 2015; Delettre et al., 2000; Waterham et al., 2007). We hypothesized that defects in these genes could also cause small-fiber neuropathy (SFN). The clinical picture of SFN is dominated by sensory symptoms, including neuropathic pain and altered temperature sensation, and signs of autonomic dysfunction. For the diagnosis SFN, a decreased small-nerve fiber density in skin biopsy and/or abnormal temperature thresholds in quantitative sensory testing are required (Hoeijmakers et al., 2012). Histologically, in SFN the thinmyelinated A $\delta$-fibers and unmyelinated C-fibers are affected. Especially, small-diameter-unmyelinated-nerve fibers appear to be susceptible for mitochondrial dysfunction, because of the high number of mitochondria per axonal volume compared to myelinated axons (Flatters, 2015; Persson et al., 2016). In addition, increased numbers of mitochondria are found in the free nerve endings (Baloh, 2008). These features could contribute to a length-dependent pattern, with longer nerve fibers being affected first, clinically reflected in sensory symptoms starting distally in the extremities (Persson et al., 2016).

We investigated the role of opa1 and gdap 1 in SFN by using established morpholinos (MO) to knockdown these genes in zebrafish and testing the effects on mitochondrial morphology, nerve density in the caudal fin and temperature-related activity (Rahn et al., 2013; Gonzaga-Jauregui et al., 2015).

\section{Methods}

\subsection{Zebrafish husbandry}

Zebrafish (Danio rerio) were housed and raised in the zebrafish facility at Maastricht University as previously described (Eijkenboom et al., 2019). To obtain eggs for microinjections, males and females were placed in a breeding tank and separated by a plastic divider. The next morning, after the lights were turned on, mating was allowed by 
A

\section{Gdap1 Knockdown}

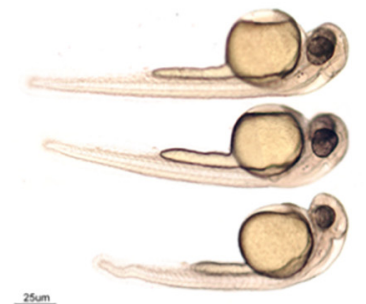

Control MO Normal

Gdap1 MO Normal

Gdap1 MO Hammer Tail

$25 \mathrm{sm}$

C
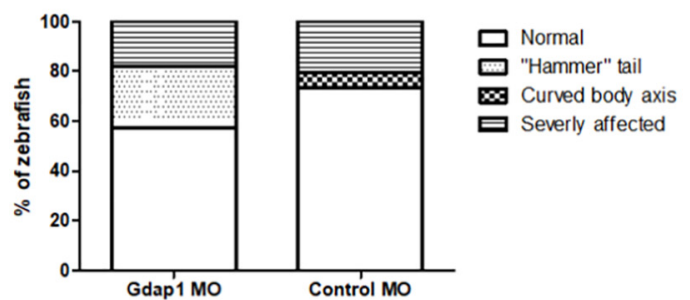

B

\section{Opa1 Knockdown}

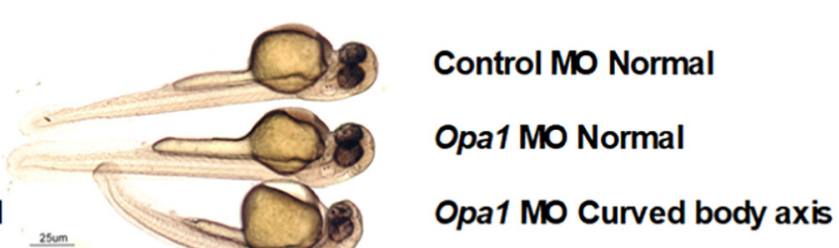

D
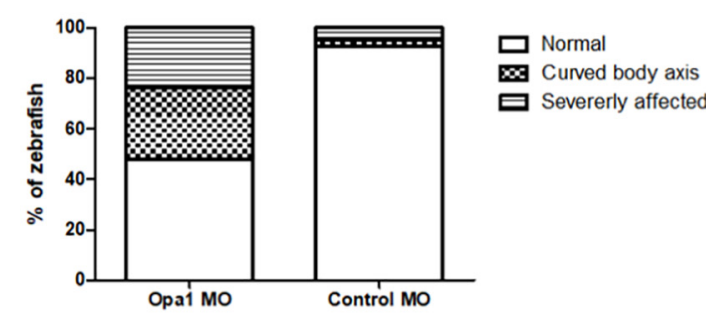

Fig. 2. Phenotypes at 2dpf after gdap1 and opa1 morpholino (MO) knockdown.

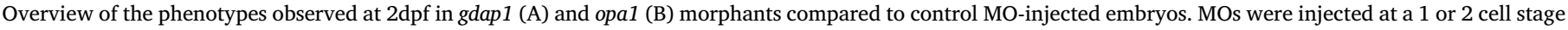

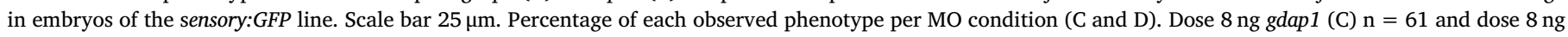
control MO-injected (C) embryos $n=34$, dose $8.5 \mathrm{ng}$ opa1 (D) $n=100$, dose $8.5 \mathrm{ng}$ Control MO-injected embryos (D) $n=82$.

removing the divider. Embryos were raised in petri-dishes containing E3 water (Nusslein-Volhard and Dahm, 2002). O'Brien and coworkers developed and described the sensory:GFP line used in our study (O'brien et al., 2012). Briefly, this transgenic line makes use of the UAS/GAL4 expression system where an enhancer of the islet-1 (isl[ss]) gene drives expression of GAL4-VP16 and thereby activates GFP under the control of 14 copies of the Gal4 upstream activating sequences (UAS). For all imaging studies, to avoid interference of pigmentation with the fluorescent signal, a sensory:GFP line in a nacre background was used lacking melanophores (Lister et al., 1999).

\subsection{Morpholino injections}

The gdap1 and opa1 MO were obtained from Gene Tools, LLC (Philomath,OR, USA). The gdap1 is a splice-blocking MO and the opa1 MO targets the 5'UTR. Both MOs were injected in the 1-or 2-cellular stage in sensory:GFP embryos or in $\mathrm{AB}$ wildtype (WT) embryos at a previously reported dose (Gonzaga-Jauregui et al., 2015; Rahn et al., 2013). It is recommended to test MOs according to the recently published guidelines (Stainier et al., 2017). Since both MOs were already published (the phenotypes described in these papers were clear and matched with the phenotypes we observed) and an efficient knockdown was reported, we considered it not necessary to perform dose-response curves and rescue experiments.

\subsection{Confocal imaging \& quantification}

At 2 days post-fertilization (dpf) gdap1, opa1 and control morphants were anesthetized using tricaine mesylate (Saint Louis, MO, USA) and were embedded in agarose. Imaging was performed with a DMI 4000B microscope (Leica, Wetzlar, Germany) equipped with a TCS SPE confocal laser scanning module (Leica, Wetzlar, Germany). For the nerve density studies, the caudal fin was imaged, with a $20 \times$ magnification, for each embryo to achieve reproducibility between embryos. Image acquisition was performed using confocal slices of $1.01 \mu \mathrm{m}$. To perform noise reduction LAS X software (version 3.3) was used. Each confocal recording was loaded in ImageJ software (version 1.50i) and $\mathrm{z}$ - projections were converted to 8-bit images. After manually adjusting the threshold based on the original z-projection, nerve densities were quantified in the caudal fin using the ImageJ Particle Analyzer. For each image, the mean pixel value was quantified in five independent areas chosen at random in the tail section, which were subsequently averaged. For analysis default settings of the Particle Analyzer were used (Eijkenboom et al., 2019). To visualize mitochondrial networks in dermal cells, MO-injected embryos were incubated for $3,5 \mathrm{~h}$ at $28.5^{\circ} \mathrm{C}$ with Mitotracker Orange CMTMRos (Thermo Fisher Scientific, Waltham $\mathrm{MA}$ ) at a concentration of $1 \mu \mathrm{M}$ which was diluted in E3 water without the addition of methylene blue, using a $63 \times$ confocal microscope objective lens and a $1.5 \times$ digital zoom factor. $2 \mathrm{D}$ mitochondrial network analysis was performed blinded using a recently published macro tool for ImageJ (MiNA v110) (Valente et al., 2017). Next, to several image enhancing steps this macro creates a skeleton of the mitochondrial network and calculates several factors including the number of individual structures, the number of networks and the mean branch length of rods/branches. For a complete description of this macro and the other parameters that are calculated, we refer to Valente et al. (Valente et al., 2017).

\subsection{ZebraBox experiments}

A temperature-controlled water compartment, developed by our group in collaboration with Maastricht Instruments BV., was used to assess temperature-related activity (Eijkenboom et al., 2019). This water compartment was used as an add-on to a customized ZebraBox system (Viewpoint, Lyon, France). Because the system contains 2 water reservoirs with water at a high temperature and water at a baseline temperature $\left(28^{\circ} \mathrm{C}\right)$, standardized temperature for raising zebrafish embryos, we were able to rapidly increase the water temperature in the compartment (Kimmel et al., 1995). At 4 dpf, zebrafish larvae with an AB WT background, injected with the gdap1, opa1 or control MO were transferred to a 48 well plate containing $500 \mu \mathrm{E} 3$. The plate containing the larvae was placed in the ZebraBox and after an adaptation time of $30 \mathrm{~min}$ in the dark, at $28.5^{\circ} \mathrm{C} \pm 0.1^{\circ} \mathrm{C}$, the experimental protocol was initiated. The protocol started with a baseline recording of $10 \mathrm{~min}$ at 
A

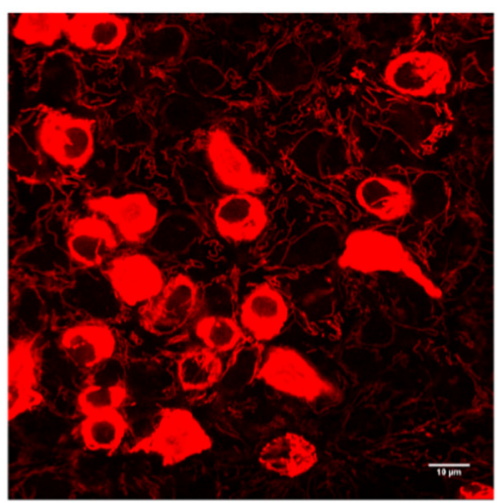

Opa1 MO

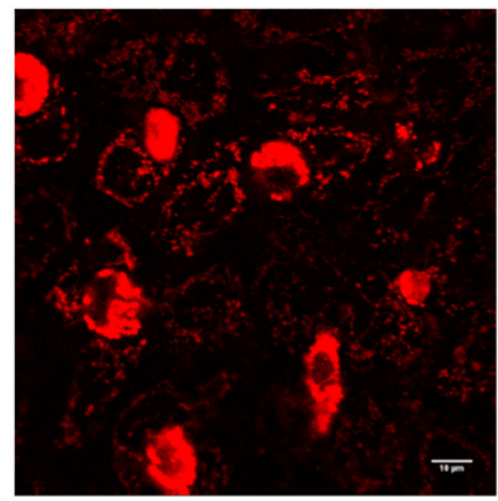

Control MO

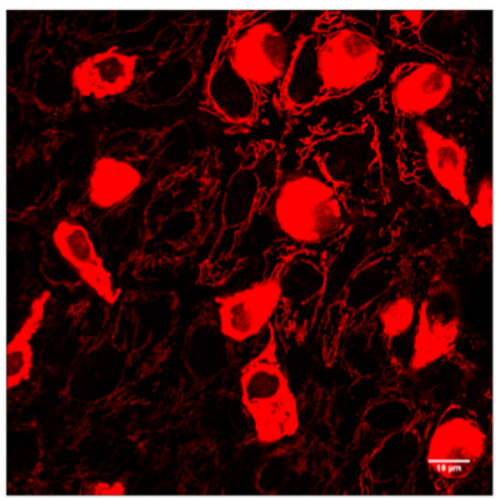

B

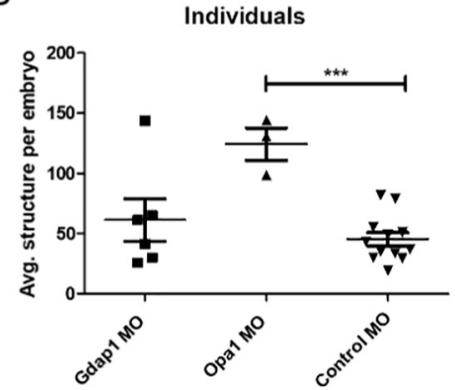

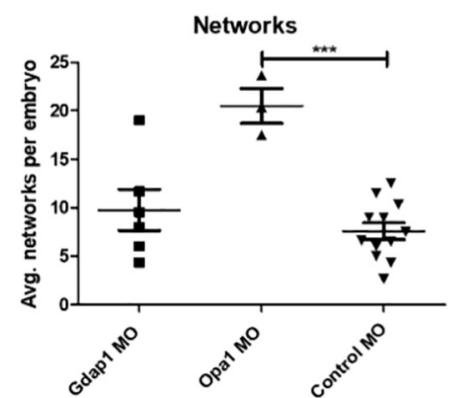

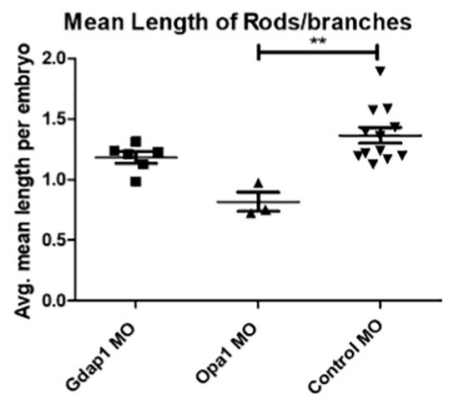

Fig. 3. Mitochondrial networks in gdap1 and opa1 depleted embryos.

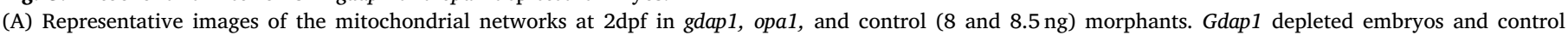

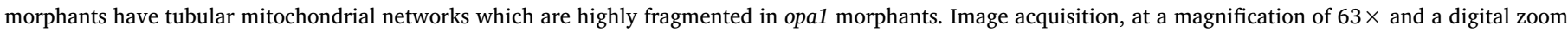

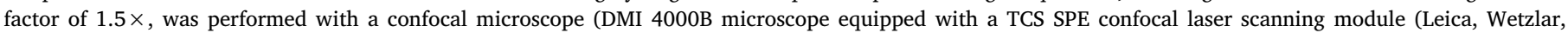

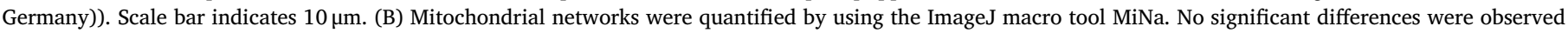

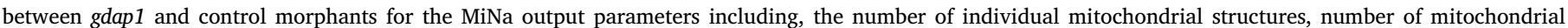

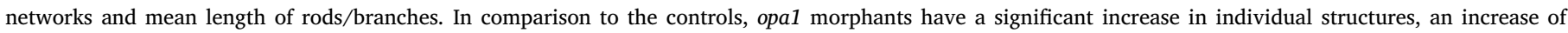

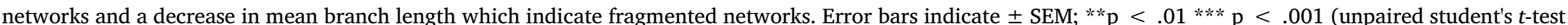
with a Bonferroni correction for multiple testing). $\mathrm{n}^{\text {gdap } 1 \text { hammer tail }}=6 ; \mathrm{n}^{\text {Opa1 bend body axis }}=3 ; \mathrm{n}^{\text {control } 8 \mathrm{ng} / 8.5 \mathrm{ng}}=12$.

$28.0^{\circ} \mathrm{C} \pm 0.1^{\circ} \mathrm{C}$ and was followed by an increase of the water temperature with a maximum temperature of $36.5^{\circ} \mathrm{C} \pm 0.4^{\circ} \mathrm{C}$ for the gdap1 experiments and $35.8{ }^{\circ} \mathrm{C} \pm 0.4^{\circ} \mathrm{C}$ for the opa1 experiments. Since the water inside the wells is indirectly heated by the arena, the actual temperature inside the wells is slightly lower. Zebralab software determined the size of the zebrafish by contrast differences between zebrafish and background. The software recorded the movement of the zebrafish and determined the activity by the number of pixels that change from one frame to the next. This data (changes in pixels) was expressed using Arbitrary Units (AU).

\subsection{Statistical analysis}

GraphPad Prism version 5.02 was used to carry out statistical analysis (Student's $t$-test). Data were considered significant when the calculated p-value $<.05$. To correct for multiple testing in the mitochondrial network studies we applied the Bonferroni correction. All data is presented as standard error of the mean (SEM).

\section{Results}

\subsection{Phenotype of gdap1 and opa1 morphants}

Gdap1 knockdown revealed a distinct phenotype observed in $24.6 \%$ of the embryos (Fig. 2A, C). In these embryos, we observed a hammershaped tail (Fig. 2A,C) which was not reported before for these morphants. The opa1 morphants were classified at $2 \mathrm{dpf}$ in three groups; embryos mildly affected, with as main phenotypic characteristics a curved body axis, non-affected and severely-affected embryos (Fig. 2B,D), comparable to what has been described before (Rahn et al., 2013). The severe groups were excluded from further analysis.

\subsection{Dermal cells of zebrafish embryos have tubular mitochondrial networks which are fragmented after opa1 knockdown}

To investigate, in vivo, the effect of a knockdown of gdap1 and opa1 on mitochondrial network morphology, we stained the mitochondria of embryos with a distinct phenotype at 2dpf with Mitotracker Orange CMTMRos. Mitotracker staining was only achieved in the enveloping and basal skin layer of the embryo. For both, control and gdap1 morphants, we observed tubular mitochondrial networks (Fig. 3A), while for the opa1 morphants the mitochondrial networks were fragmented (Fig. 3A). Quantification of these images with the freely available MiNa tool (Valente et al., 2017) demonstrated no significant differences between gdap1 and control morphants (Fig. 3B). For the opa1 morphants, we observed a significant increase in individual mitochondria with an increase in smaller networks (Fig. 3B).

\subsection{Nerve densities in gdap1 and opa1 morphants}

Next, we assessed the effect of the gdap1 and opa1 knockdown on sensory neurite development using the transgenic sensory:GFP zebrafish 
A

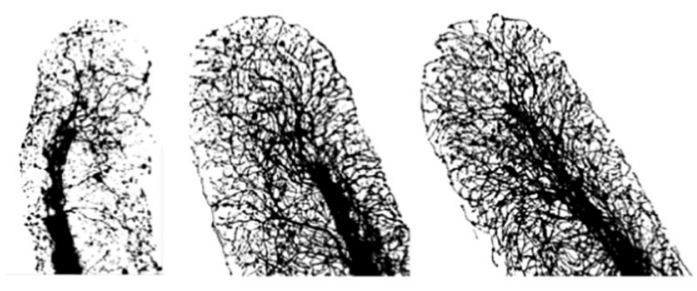

C
B

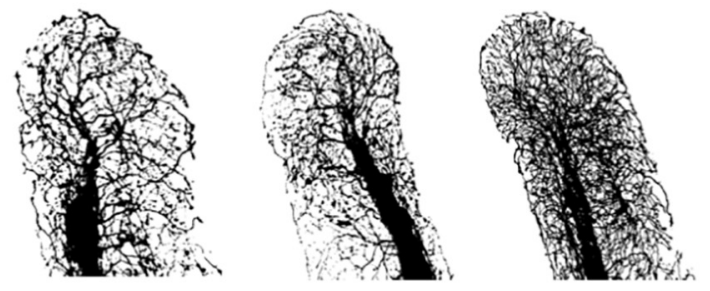

D
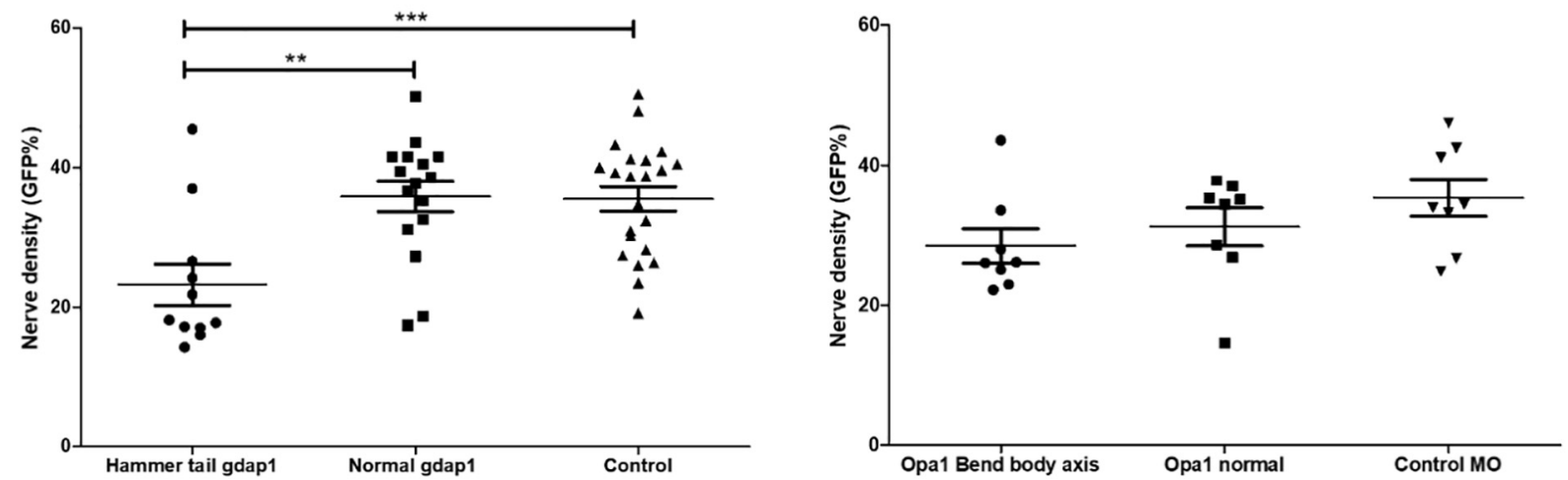

Fig. 4. Reduced nerve densities at 2dpf in gdap1 and opa1 morphants.

Representative maximal projections of confocal recordings (20× magnification) of zebrafish tail sections of gdap1 (A) and opa1 (B) morphants compared with 8 ng control MO-injected embryos (A) or $8.5 \mathrm{ng}$ control MO-injected embryos (B). A significantly lower nerve density in gdap1 morphants with a "hammer" tail is revealed after quantification of the nerve densities (\%GFP) in gdap1 (C) and opa1 (D) morphants by using the ImageJ particle analyzer (analyzing per embryo 5 independent areas). Error bars indicate \pm SEM; $* * \mathrm{p}<.01 * * * \mathrm{p}<.001$ (unpaired student's $t$-test). $\mathrm{n}^{\text {gdap } 1 \text { hammer tail }}=11 ; \mathrm{n}^{\text {gdap } 1 \text { normal }}=16 ; \mathrm{n}^{\text {control dose } 8 \mathrm{ng}}=22 ; \mathrm{n}^{\text {Opa1 } 1 \text { bend body }}$ axis $=8 ; \mathrm{n}^{\text {Opa1 normal }}=8 ; \mathrm{n}^{\text {control dose } 8.5 \mathrm{ng}}=8$.

line, marking all sensory neurons. Knocking down the mitochondrial protein gdap1 has a significant effect on the development of sensory neurites (Fig. 4A). A lower density of sensory neurites is observed in gdap1 morphants with a "hammer" tail phenotype $(23.2 \% \pm 3.0$, $\mathrm{n}=11)$ compared to control MO-injected embryos $(35.5 \% \pm 1.8$, $\mathrm{n}=22$, p-value 0.006$)$ and gdap1 morphants without this phenotype $(35.9 \% \pm 2.2, \mathrm{n}=16, \mathrm{p}$-value 0.0018$)$ (Fig. 4A,C). Between the gdap1 knockdown without the "hammer" tail and the control-MO injected no differences in the nerve density was observed (p-value 0.909). At $2 \mathrm{dpf}$ for embryos with a knockdown of opa1, no significant differences in the density of sensory neurites (bend body axis $28.4 \% \pm 2.5, \mathrm{n}=8$ and normal $31.2 \pm 2.8, \mathrm{n}=8$ ) was observed compared to control MO-injected embryos $(35.3 \pm 2.6, \mathrm{n}=8)$ (Fig. $4 \mathrm{~B}, \mathrm{D})$.

\subsection{Temperature sensitivity of gdap1 and opa1 morphants}

The effect of the gdap1 and opa1 knockdown on temperature sensitivity was tested in larvae with normal morphology to avoid interference of the morphological deformities in swimming behavior. After an adaptation time of $30 \mathrm{~min}$ and baseline recording at $28.5^{\circ} \mathrm{C} \pm 0.1^{\circ} \mathrm{C}$ the larvae were exposed to a rapid temperature change with a maximum temperature of $36.5^{\circ} \mathrm{C} \pm 0.4^{\circ} \mathrm{C}$ for the gdap 1 experiments and $35.8{ }^{\circ} \mathrm{C} \pm 0.4^{\circ} \mathrm{C}$ for the opa1 morphants (Fig. 5). As reported before, wild-type zebrafish larvae responded to the temperature change with an increased swimming activity which further increased as the temperature rose (Prober, Zimmerman et al. 2008). A significantly reduced temperature response for gdap1 morphants was observed, while for opa1 morphants a similar response as control-injected larvae was observed (Fig. 5A,B). For all groups, the activity of larvae reached its maximum during heating and subsequently declined (Fig. 5A,B). All larvae survived the heating protocol and no defects or abnormalities were observed afterwards.

\section{Discussion}

\subsection{Depletion of mitochondrial gdap1 in zebrafish affected sensory nerve} density and temperature sensitivity

We showed that a gdap1 knockdown in zebrafish embryos caused a distinct phenotype with a decreased sensory nerve density, but with no visible effect on mitochondrial network morphology in dermal cells. For the subgroup, without a morphological defect in this early stage, we did not observe a decreased density of sensory neurites. However, these embryos had at a later developmental stage (4dpf) a diminished temperature response indicative of having a disturbed development of dorsal root ganglia which take over the function of processing sensory input of Rohon Beard neurons (Malafoglia et al., 2013).

GDAP1 is a tail-anchored protein located in the mitochondrial outer membrane and is highly expressed in the nervous system (Niemann et al., 2005; Pedrola et al., 2005; Cuesta et al., 2002). GDAP1 knockdown in an N1E-115 neuroblastoma cell line using RNAi revealed a more tubular mitochondrial network, indicating a shift towards fusion (Niemann et al., 2005). Mitochondrial networks in patient fibroblasts harboring a dominant missense mutation were partially fragmented and had an increase of the diameter of mitochondria (Cassereau et al., 2009). Furthermore, several other studies described a role for GDAP1 in mitochondrial fission (Niemann et al., 2009; Wagner et al., 2009). Knockdown studies with other fission factors revealed a DRP1 and FIS1 


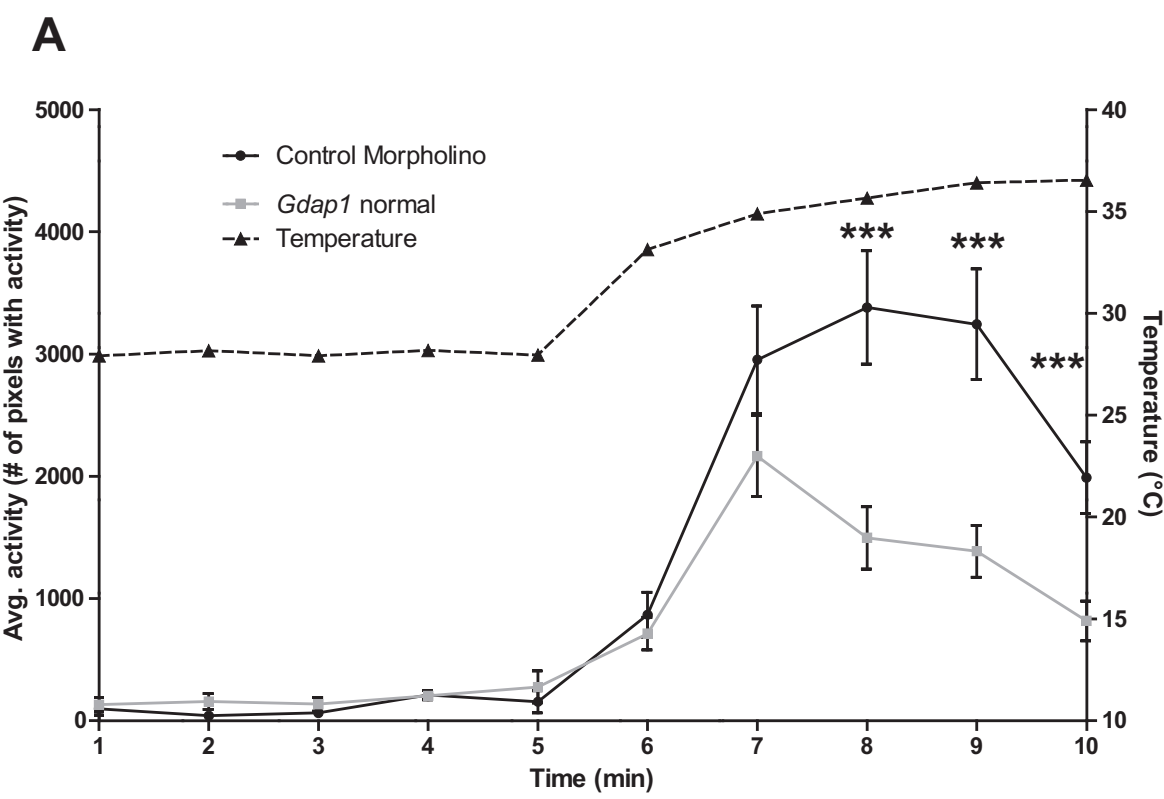

B

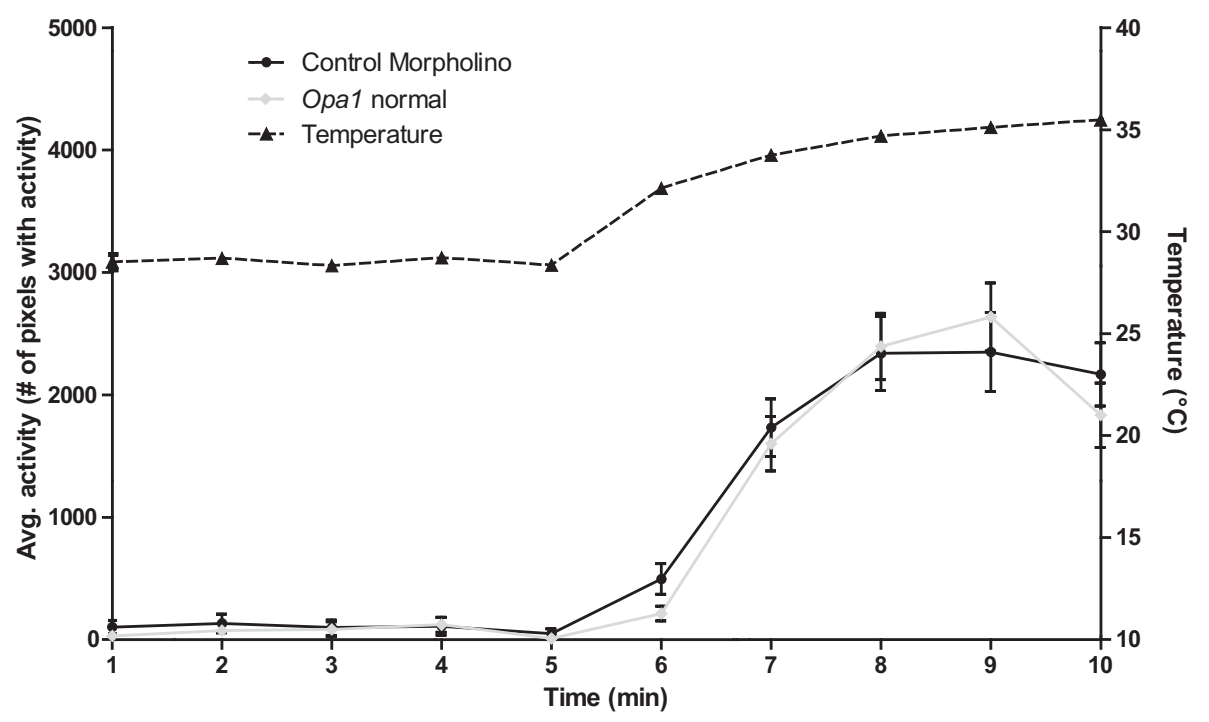

Fig. 5. Decreased swimming activity at elevated temperatures for larvae with a knockdown of gdap1. At 4dpf morphologically normal zebrafish morphants of gdap1 and opa1 or injected with the control morpholino were exposed to an elevation of water temperature (dotted line and right y-axis) after baseline recording. This resulted in a significantly decreased activity at elevated temperatures for larvae with a knockdown of gdap1 (grey line panel A). For larvae with a knockdown of opa1 (grey line panel B), no difference in activity was observed. Each data point represents the mean value with SEM. (A) $\mathrm{n}^{\text {gdap } 1}=48, \mathrm{n}^{\text {control-MO }}=48$. (B) $\mathrm{n}^{\text {opa1 }}=69, \quad \mathrm{n}^{\text {control-MO }}=65 . * *$ Significance was tested with an unpaired student's $t$-test (unequal variances) and was demonstrated for 3 time points, 8,9 and 10 , in panel A. $* * *$ indicates $\mathrm{p}$ values $<$ .001 . Activity is presented as changes in pixels and is expressed using Arbitrary Units (AU). dependent role for GDAP1 (Niemann et al., 2009). In contrast, PlaMartín et al. did not observe an increase in mitochondrial tubulation in a gdap1 knock-down human neuroblastoma cell line (Pla-Martin et al., 2013). They reported an increase of mitochondria, however, with normal elongation indexes and a decrease of mitochondrial interconnectivity (Pla-Martin et al., 2013). This is more in line with what we observe by staining the mitochondrial network in dermal cells of the zebrafish gdap1 knockdown model. However, as we were not able to visualize the neurons and used zebrafish, which were only slightly abnormal, it could well be that subtle changes in the mitochondrial network remained undetected. These differences indicate that the exact, and maybe tissue-specific role of GDAP1 in fission and mitochondrial network formation is more complex than anticipated.

Mitochondrial fission has been linked to neuron development before (Ishihara et al., 2009; Liu et al., 1999). For example, overexpression of the mitochondrial fission protein $D R P 1$ increased neuronal differentiation (Ishihara et al., 2009). An important role for GDAP1 in neuron development was illustrated by the upregulation of this gene during neuronal differentiation (Liu et al., 1999). As we provided evidence for a role of GDAP1 in sensory neuron development at an early embryonic stage, it is possible that the defects in neuron development might already arise at the first step of neuronal differentiation from stem cells. Neuronal stem cells (NSC) have tubular mitochondrial networks and mainly rely on glycolytic ATP production (Khacho et al., 2016). Glycolysis provides important building blocks for the synthesis of amino acids, lipids and nucleic acids important for self-renewal (Chen and Chan, 2017). Interference of mitochondrial dynamics in these uncommitted cells revealed no effect on cell number or viability (Khacho et al., 2016). However, MFN1/2 deficiencies resulted in more fragmented mitochondria accompanied by an enhancement of cells transitioning to a committed progenitor state and a decrease in self-renewal, while the opposite was observed for cells with a loss of DRP1 (Khacho et al., 2016). This increase in transitioning is associated with elevated levels of Reactive oxygen species (ROS) and an upregulation of genes involved in neuronal differentiation (Isl1, Olig2, Lhx5, Nkx2.1, Sim1), redox response (Aldh1l2 and Slc7a11/xCT) and the Notch pathway (Botch/CHAC1). Since Isl1 is an important marker for sensory neurons (Sun et al., 2008), we hypothesize that a loss of GDAP1 might 


\section{NSC to committed progenitor cell}

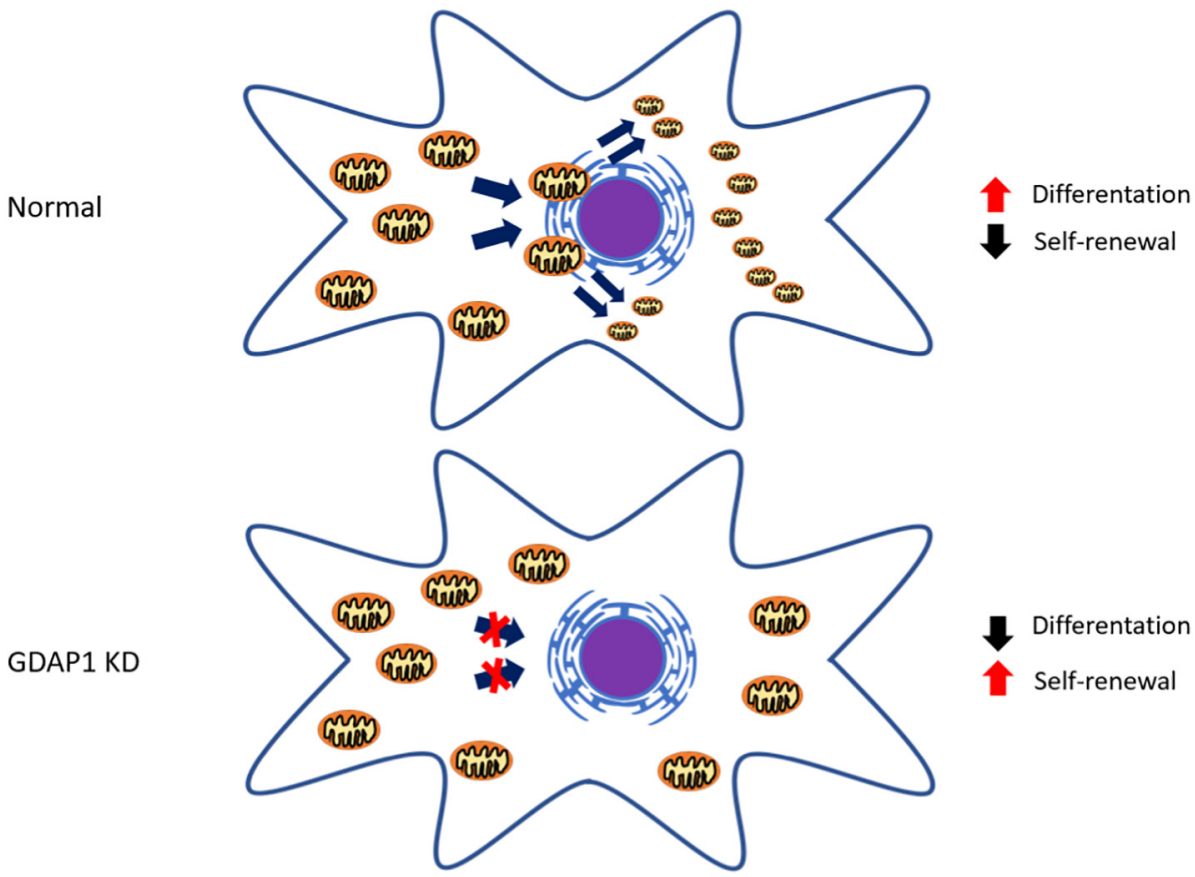

Fig. 6. Mitochondrial dynamics during the transition of neuronal stem cell (NSC) to committed progenitor cell in WT and GDAP1-depleted cells. The upper panel shows the transition of NSC to committed progenitor cells in WT cells. Mitochondrial fission initiated at the ER results in the formation of two daughter mitochondria. Subsequently, this results in an increase in ROS production by OXPHOS which in turn leads to upregulation of genes important in neuronal differentiation, redox response, and Notch signaling. The lower panel shows the transition of NSC to committed progenitor cells in GDAP1-depleted cells. Knockdown (KD) of GDAP1 affects according to the group of Nieman (Niemann et al., 2005) mitochondrial fission, we hypothesize by a defect in transport to the ER, resulting in elongated mitochondria and no increase in ROS production and thereby a balance towards self-renewal rather than differentiation.

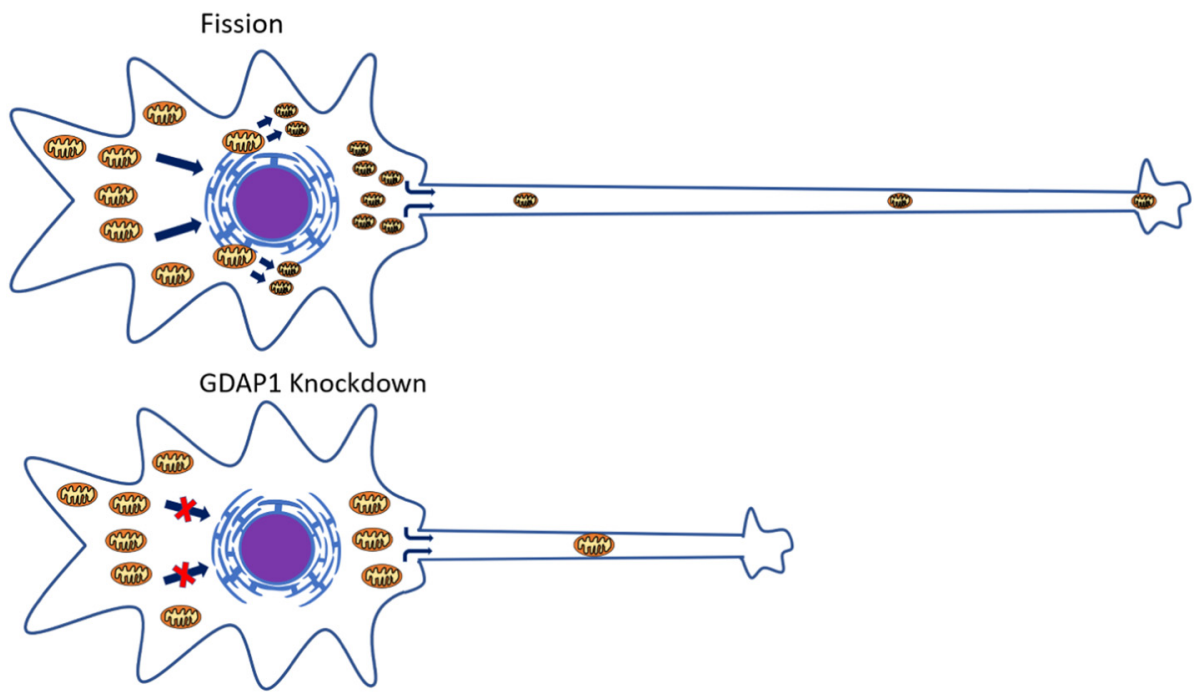

Fig. 7. Mitochondrial fission in differentiated sensory neurons. (A) Mitochondrial fission initiated at the ER results in the formation of two daughter mitochondria. In order to provide energy production in the distal regions mitochondria are normally distributed by microtubule transport along the neurites. (B) According to literature, depletion of GDAP1 affects mitochondrial fragmentation (Niemann et al., 2005) and results in elongated mitochondria which cannot be transported towards the most distal regions resulting in a decrease of ATP supply, $\mathrm{Ca}^{2+}$ homeostasis and lipid metabolism which halts the outgrowth of neurites.

additionally promote self-renewal rather than cell differentiation in sensory neurons (Fig. 6).

In addition to a limited neural differentiation, caused by a defect in mitochondrial fragmentation, a shift towards fusion probably resulted in a disturbed transport of the un-fragmented mitochondria. It has been proposed that defects in mitochondrial fission results in mitochondrial aggregation in the soma and an abnormal distribution of mitochondria in neurites, causing ATP depletion, disturbed $\mathrm{Ca}^{2+}$ homeostasis and a decreased lipid metabolism (Otera et al., 2013; Pla-Martin et al., 2013; Gonzalez-Sanchez et al., 2017). Probably these local energy deficits affected the formation of the outgrowth of sensory neurites (Fig. 7). Besides the inability of transport of these elongated organelles, a more distinct role in mitochondrial transport has been implicated for GDAP1 since interactions with the cytoskeleton and trafficking-associated proteins like B-tubulin, $R A B 6 B$, and caytaxin have been demonstrated (Pla-Martin et al., 2013). In GDAP1 depleted cells, mitochondria were misallocated and were not transported towards the subplasmalemmal domain upon ER-Ca ${ }^{2+}$ emptying and SOCE activation, leading to defects in $\mathrm{Ca}^{2+}$ homeostasis (Pla-Martin et al., 2013, Gonzalez-Sanchez et al., 2017). In addition, a lower number of mitochondria were colocalized with the ER in GDAP1 depleted cells (Pla-Martin et al., 2013). The ER is an important site for mitochondrial fission since mitochondrial division sites are marked by ER tubules that wrap around the mitochondria (Friedman et al., 2011). These data suggest that knockdown or loss of GDAP1 prevented the localization of mitochondria to the ER and inhibited mitochondrial fission and transport.

Our study revealed a significantly reduced density of sensory neurites, whereas a previous study of the same gdap1 knockdown model revealed that embryos had defects in peripheral motor neuron axon branching, extension, and pathfinding. In this study, co-injection with MOs at sub-effective doses, targeted towards, $m f n 2$ and abhd12, genes also involved in peripheral neuropathies, revealed an exacerbation of the phenotype (Gonzaga-Jauregui et al., 2015).

Based on similarities in neuroanatomical structures between 
zebrafish and mammals and on the decreased temperature-related activity, our results are indicative of an altered pain perception in gdap1depleted zebrafish embryos (Malafoglia et al., 2013). Pathogenic variants in GDAP1 can cause four subtypes of CMT, with a variation in inheritance pattern and neurophysiology features (Cassereau et al., 2011). The autosomal recessive form causes a severe early-onset of the disease and these mutations result in a decreased mitochondrial fission activity (Niemann et al., 2009; Auer-Grumbach et al., 2008; Dubourg et al., 2006). Overlap in the phenotype of patients with CMT and SFN together with our data in zebrafish, suggest that GDAP1 mutations could play a role in the development of SFN due to a defect in sensory neuron development at an early developmental stage (Zambelis, 2009; Laura et al., 2014; Pazzaglia et al., 2010; Tavakoli et al., 2012). Furthermore, we expect that similar mechanisms could be involved in the axonal nerve degeneration in patients with SFN and our model. In gdap1 morphants, we observe a neurodevelopmental defect which is possibly caused by energy deficits as a result of a disturbed mitochondrial distribution. It has been reported that SFN patients, in an early stage without IENF loss, already have a reduction of mitochondria in these nerves. Therefore, a loss of mitochondria precedes nerve degeneration (Casanova-Molla et al., 2012). These local energy deficits could play a key role in the development of the disease.

\subsection{Opa1 depletion has no effect on zebrafish embryo sensory nerve densities and temperature sensitivity}

As reported before and observed in our study zebrafish embryos with opa1 knockdown presented with smaller eyes, reduced touch response, unlooped hearts and pericardial edema (Rahn et al., 2013). In the current study, the opa1 morphants were categorized according to their main characteristic feature, a severely bend body axis at $2 \mathrm{dpf}$. However, a deficiency of opa1 did not reveal any differences in sensory neurite nerve density nor an effect on temperature sensitivity, indicating that also at a later stage in development (4dpf) there was no effect in the sensory neurons. Our results suggest that a loss of OPA1, located in the inner mitochondrial membrane and important in mitochondrial fusion, has no effect on the sensory neurite development at an early developmental stage. Defects in mitochondrial fusion promote mitochondrial fragmentation, which is driving early neuronal development without, at this stage, a negative effect on neuronal differentiation (Khacho et al., 2016). Furthermore, no defects in transport to the distal areas seem to occur, in line with proper fragmentation of mitochondria. However, as we only studied one of the fusion factors during early embryonic development, this data does not rule out a role for opa1 or fusion in general in axonal degeneration at juvenile or adult stages in the zebrafish (Persson et al., 2016). Depletion of the outer membrane fusion proteins MFN1 and MFN2 should confirm these observations.

In conclusion, we have demonstrated a role for gdap1, but not for opa1 in sensory neurite development, leading to SFN characteristics in zebrafish. Our findings revealed deficient neurodevelopment, however, we did not observe a defect in mitochondrial fission. This may be because we could not study the mitochondrial networks in the developing neurites or because other mechanisms could apply. Although, we do not observe an effect of interference with mitochondrial fusion at this developmental stage, we still propose that genes involved in mitochondrial dynamics should be screened for mutations in patients with SFN.

\section{Funding}

Development of the temperature-controlled arena was supported by the Alma in Silico project, which is financed by the Interreg IV European funds, The Walloon Region, The North Rhine Westphalia, The Flemish Community, The Belgian Province of Limburg and The Dutch Province of Limburg, as well as by the Universities of Maastricht and Liège. This work was also supported by the European Union Seventh
Framework Programme (FP-7 grant 602273). M.G. is supported by the Dutch province of Limburg and the stichting Metakids. We also want to acknowledge the Guy Peeters Fonds for their financial contributions.

\section{Competing interests}

The authors declare no competing or financial interests.

\section{Authors contribution statement}

Conceptualization: I.E., J.M.V., J.G.J.H., H.J.M.S.; Methodology I.E., J.M.V., J.G.J.H., H.J.M.S.; Validation: I.E., J.M.V.; Formal analysis: I.E., I.W.; Investigation: I.E., I.W; Resources: H.J.M.S., C.G.F.; Writing original draft: I.E., H.J.M.S.; Writing - review \& editing: J.G.J.H., M.G., I.W., H.J.M.S., C.G.F., J.M.V.; Visualization: I.E.; Supervision: J.M.V., H.J.M.S., C.G.F.; Funding acquisition: H.J.M.S., C.G.F., J.M.V.

\section{Acknowledgments}

We thank the lab of Dr. A. Sagasti for kindly providing the transgenic sensory:GFP line, IDEE (Maastricht UMC+) and Maastricht Instruments BV. for the development of the ZebraBox add-on and their technical support.

\section{References}

Abrams, A.J., Hufnagel, R.B., Rebelo, A., Zanna, C., Patel, N., Gonzalez, M.A., Campeanu, I.J., Griffin, L.B., Groenewald, S., Strickland, A.V., Tao, F., Speziani, F., Abreu, L., Schule, R., Caporali, L., La Morgia, C., Maresca, A., Liguori, R., Lodi, R., Ahmed, Z.M., Sund, K.L., Wang, X., Krueger, L.A., Peng, Y., Prada, C.E., Prows, C.A., Schorry, E.K., Antonellis, A., Zimmerman, H.H., Abdul-Rahman, O.A., Yang, Y., Downes, S.M., Prince, J., Fontanesi, F., Barrientos, A., Nemeth, A.H., Carelli, V., Huang, T., Zuchner, S., Dallman, J.E., 2015. Mutations in SLC25A46, encoding a UGO1-like protein, cause an optic atrophy spectrum disorder. Nat. Genet. 47, 926-932.

Auer-Grumbach, M., Fischer, C., Papic, L., John, E., Plecko, B., Bittner, R.E., Bernert, G., Pieber, T.R., Miltenberger, G., Schwarz, R., Windpassinger, C., Grill, F., Timmerman, V., Speicher, M.R., Janecke, A.R., 2008. Two novel mutations in the GDAP1 and PRX genes in early onset Charcot-Marie-Tooth syndrome. Neuropediatrics 39, 33-38.

Baloh, R.H., 2008. Mitochondrial dynamics and peripheral neuropathy. Neuroscientist $14,12-18$.

Bertholet, A.M., Delerue, T., Millet, A.M., Moulis, M.F., David, C., Daloyau, M., ArnaunePelloquin, L., Davezac, N., Mils, V., Miquel, M.C., Rojo, M., Belenguer, P., 2016. Mitochondrial fusion/fission dynamics in neurodegeneration and neuronal plasticity. Neurobiol. Dis. 90, 3-19.

Casanova-Molla, J., Morales, M., Garrabou, G., Sola-Valls, N., Soriano, A., Calvo, M., Grau, J.M., Valls-Sole, J., 2012. Mitochondrial loss indicates early axonal damage in small fiber neuropathies. J. Peripher. Nerv. Syst. 17, 147-157.

Cassereau, J., Chevrollier, A., Gueguen, N., Malinge, M.C., Letournel, F., Nicolas, G., Richard, L., Ferre, M., Verny, C., Dubas, F., Procaccio, V., Amati-Bonneau, P., Bonneau, D., Reynier, P., 2009. Mitochondrial complex I deficiency in GDAP1-related autosomal dominant Charcot-Marie-Tooth disease (CMT2K). Neurogenetics 10, $145-150$.

Cassereau, J., Chevrollier, A., Gueguen, N., Desquiret, V., Verny, C., Nicolas, G., Dubas, F., Amati-Bonneau, P., Reynier, P., Bonneau, D., Procaccio, V., 2011. Mitochondrial dysfunction and pathophysiology of Charcot-Marie-Tooth disease involving GDAP1 mutations. Exp. Neurol. 227, 31-41.

Chen, H., Chan, D.C., 2009. Mitochondrial dynamics_fusion, fission, movement, and mitophagy - in neurodegenerative diseases. Hum. Mol. Genet. 18, R169-R176.

Chen, H., Chan, D.C., 2017. Mitochondrial dynamics in regulating the unique phenotypes of cancer and stem cells. Cell Metab. 26, 39-48.

Cuesta, A., Pedrola, L., Sevilla, T., Garcia-Planells, J., Chumillas, M.J., Mayordomo, F., Leguern, E., Marin, I., Vilchez, J.J., Palau, F., 2002. The gene encoding gangliosideinduced differentiation-associated protein 1 is mutated in axonal Charcot-MarieTooth type 4A disease. Nat. Genet. 30, 22-25.

Delettre, C., Lenaers, G., Griffoin, J.M., Gigarel, N., Lorenzo, C., Belenguer, P., Pelloquin, L., Grosgeorge, J., Turc-Carel, C., Perret, E., Astarie-Dequeker, C., Lasquellec, L., Arnaud, B., Ducommun, B., Kaplan, J., Hamel, C.P., 2000. Nuclear gene OPA1, encoding a mitochondrial dynamin-related protein, is mutated in dominant optic atrophy. Nat. Genet. 26, 207-210.

Dubourg, O., Azzedine, H., Verny, C., Durosier, G., Birouk, N., Gouider, R., Salih, M., Bouhouche, A., Thiam, A., Grid, D., Mayer, M., Ruberg, M., Tazir, M., Brice, A. Leguern, E., 2006. Autosomal-recessive forms of demyelinating Charcot-Marie-Tooth disease. NeuroMolecular Med. 8, 75-86.

Eijkenboom, I., Sopacua, M., Otten, A.B.C., Gerrits, M.M., Hoeijmakers, J.G.J., Waxman, S.G., Lombardi, R., Lauria, G., Merkies, I.S.J., Smeets, H.J.M., Faber, C.G., Vanoevelen, J.M., Group, P.S., 2019. Expression of pathogenic SCN9A mutations in the zebrafish: A model to study small-fiber neuropathy. Exp. Neurol. 311, 257-264. Flatters, S.J., 2015. The contribution of mitochondria to sensory processing and pain. 
Prog. Mol. Biol. Transl. Sci. 131, 119-146.

Friedman, J.R., Lackner, L.L., West, M., Dibenedetto, J.R., Nunnari, J., Voeltz, G.K., 2011. ER tubules mark sites of mitochondrial division. Science 334, 358-362.

Gonzaga-Jauregui, C., Harel, T., Gambin, T., Kousi, M., Griffin, L.B., Francescatto, L., Ozes, B., Karaca, E., Jhangiani, S.N., Bainbridge, M.N., Lawson, K.S., Pehlivan, D., Okamoto, Y., Withers, M., Mancias, P., Slavotinek, A., Reitnauer, P.J., Goksungur, M.T., Shy, M., Crawford, T.O., Koenig, M., Willer, J., Flores, B.N., Pediaditrakis, I., Us, O., Wiszniewski, W., Parman, Y., Antonellis, A., Muzny, D.M., Baylor-Hopkins Center For Mendelian, G, Katsanis, N., Battaloglu, E., Boerwinkle, E., Gibbs, R.A., Lupski, J.R., 2015. Exome sequence analysis suggests that genetic burden contributes to phenotypic variability and complex neuropathy. Cell Rep. 12, 1169-1183.

Gonzalez-Sanchez, P., Pla-Martin, D., Martinez-Valero, P., Rueda, C.B., Calpena, E., Del Arco, A., Palau, F., Satrustegui, J., 2017. CMT-linked loss-of-function mutations in GDAP1 impair store-operated ca(2+) entry-stimulated respiration. Sci. Rep. 7, 42993.

Hoeijmakers, J.G., Faber, C.G., Lauria, G., Merkies, I.S., Waxman, S.G., 2012. Small-fibre neuropathies-advances in diagnosis, pathophysiology and management. Nat. Rev. Neurol. 8, 369-379.

Hoppins, S., Nunnari, J., 2009. The molecular mechanism of mitochondrial fusion. Biochim. Biophys. Acta 1793, 20-26.

Ishihara, N., Nomura, M., Jofuku, A., Kato, H., Suzuki, S.O., Masuda, K., Otera, H. Nakanishi, Y., Nonaka, I., Goto, Y., Taguchi, N., Morinaga, H., Maeda, M. Takayanagi, R., Yokota, S., Mihara, K., 2009. Mitochondrial fission factor Drp1 is essential for embryonic development and synapse formation in mice. Nat. Cell Biol. 11, 958-966.

Khacho, M., Clark, A., Svoboda, D.S., Azzi, J., Maclaurin, J.G., Meghaizel, C., Sesaki, H., Lagace, D.C., Germain, M., Harper, M.E., Park, D.S., Slack, R.S., 2016. Mitochondrial dynamics impacts stem cell identity and fate decisions by regulating a nuclear transcriptional program. Cell Stem Cell 19, 232-247.

Kijima, K., Numakura, C., Izumino, H., Umetsu, K., Nezu, A., Shiiki, T., Ogawa, M., Ishizaki, Y., Kitamura, T., Shozawa, Y., Hayasaka, K., 2005. Mitochondrial GTPase mitofusin 2 mutation in Charcot-Marie-Tooth neuropathy type 2A. Hum. Genet. 116, 23-27.

Kimmel, C.B., Ballard, W.W., Kimmel, S.R., Ullmann, B., Schilling, T.F., 1995. Stages of embryonic development of the zebrafish. Dev. Dyn. 203, 253-310.

Laura, M., Hutton, E.J., Blake, J., Lunn, M.P., Fox, Z., Pareyson, D., Solari, A., Radice, D., Koltzenburg, M., Reilly, M.M., 2014. Pain and small fiber function in Charcot-MarieTooth disease type 1A. Muscle Nerve 50, 366-371.

Lister, J.A., Robertson, C.P., Lepage, T., Johnson, S.L., Raible, D.W., 1999. Nacre encodes a zebrafish microphthalmia-related protein that regulates neural-crest-derived pigment cell fate. Development 126, 3757-3767.

Liu, H., Nakagawa, T., Kanematsu, T., Uchida, T., Tsuji, S., 1999. Isolation of 10 differentially expressed cDNAs in differentiated Neuro2a cells induced through controlled expression of the GD3 synthase gene. J. Neurochem. 72, 1781-1790.

Malafoglia, V., Bryant, B., Raffaeli, W., Giordano, A., Bellipanni, G., 2013. The zebrafish as a model for nociception studies. J. Cell. Physiol. 228, 1956-1966.

Ni, H.M., Williams, J.A., Ding, W.X., 2015. Mitochondrial dynamics and mitochondrial quality control. Redox Biol. 4, 6-13.

Niemann, A., Ruegg, M., La Padula, V., Schenone, A., Suter, U., 2005. Ganglioside-induced differentiation associated protein 1 is a regulator of the mitochondrial network: new implications for Charcot-Marie-Tooth disease. J. Cell Biol. 170, 1067-1078.

Niemann, A., Wagner, K.M., Ruegg, M., Suter, U., 2009. GDAP1 mutations differ in their effects on mitochondrial dynamics and apoptosis depending on the mode of inheritance. Neurobiol. Dis. 36, 509-520.

Nusslein-Volhard, C., Dahm, R., 2002. Zebrafish Oxford UK.

O'brien, G.S., Rieger, S., Wang, F., Smolen, G.A., Gonzalez, R.E., Buchanan, J., Sagasti, A., 2012. Coordinate development of skin cells and cutaneous sensory axons in zebrafish. J. Comp. Neurol. 520, 816-831.
Olichon, A., Baricault, L., Gas, N., Guillou, E., Valette, A., Belenguer, P., Lenaers, G., 2003. Loss of OPA1 perturbates the mitochondrial inner membrane structure and integrity, leading to cytochrome c release and apoptosis. J. Biol. Chem. 278, 7743-7746.

Otera, H., Ishihara, N., Mihara, K., 2013. New insights into the function and regulation of mitochondrial fission. Biochim. Biophys. Acta 1833, 1256-1268.

Pareyson, D., Saveri, P., Sagnelli, A., Piscosquito, G., 2015. Mitochondrial dynamics and inherited peripheral nerve diseases. Neurosci. Lett. 596, 66-77.

Pazzaglia, C., Vollono, C., Ferraro, D., Virdis, D., Lupi, V., Le Pera, D., Tonali, P., Padua, L., Valeriani, M., 2010. Mechanisms of neuropathic pain in patients with CharcotMarie-Tooth 1 A: a laser-evoked potential study. Pain 149, 379-385.

Pedrola, L., Espert, A., Wu, X., Claramunt, R., Shy, M.E., Palau, F., 2005. GDAP1, the protein causing Charcot-Marie-Tooth disease type 4A, is expressed in neurons and is associated with mitochondria. Hum. Mol. Genet. 14, 1087-1094.

Pernas, L., Scorrano, L., 2016. Mito-Morphosis: Mitochondrial Fusion, Fission, and Cristae Remodeling as Key Mediators of Cellular Function. Annu. Rev. Physiol. 78, 505-531.

Persson, A.K., Hoeijmakers, J.G.J., Estacion, M., Black, J.A., Waxman, S.G., 2016. Sodium channels, mitochondria, and axonal degeneration in peripheral neuropathy. Trends Mol. Med. 22, 377-390.

Pla-Martin, D., Rueda, C.B., Estela, A., Sanchez-Piris, M., Gonzalez-Sanchez, P., Traba, J. De La Fuente, S., Scorrano, L., Renau-Piqueras, J., Alvarez, J., Satrustegui, J., Palau, F., 2013. Silencing of the Charcot-Marie-Tooth disease-associated gene GDAP1 induces abnormal mitochondrial distribution and affects $\mathrm{Ca} 2+$ homeostasis by reducing store-operated Ca2 + entry. Neurobiol. Dis. 55, 140-151.

Rahn, J.J., Stackley, K.D., Chan, S.S., 2013. Opa1 is required for proper mitochondrial metabolism in early development. PLoS One 8, e59218.

Scott, I., Youle, R.J., 2010. Mitochondrial fission and fusion. Essays Biochem. 47, 85-98.

Stainier, D.Y.R., Raz, E., Lawson, N.D., Ekker, S.C., Burdine, R.D., Eisen, J.S., Ingham, P.W., Schulte-Merker, S., Yelon, D., Weinstein, B.M., Mullins, M.C., Wilson, S.W., Ramakrishnan, L., Amacher, S.L., Neuhauss, S.C.F., Meng, A., Mochizuki, N., Panula, P., Moens, C.B., 2017. Guidelines for morpholino use in zebrafish. PLoS Genet. 13, e1007000.

Sun, Y., Dykes, I.M., Liang, X., Eng, S.R., Evans, S.M., Turner, E.E., 2008. A central role for Islet1 in sensory neuron development linking sensory and spinal gene regulatory programs. Nat. Neurosci. 11, 1283-1293.

Tavakoli, M., Marshall, A., Banka, S., Petropoulos, I.N., Fadavi, H., Kingston, H., Malik, R.A., 2012. Corneal confocal microscopy detects small-fiber neuropathy in CharcotMarie-Tooth disease type 1A patients. Muscle Nerve 46, 698-704.

Valente, A.J., Maddalena, L.A., Robb, E.L., Moradi, F., Stuart, J.A., 2017. A simple ImageJ macro tool for analyzing mitochondrial network morphology in mammalian cell culture. Acta Histochem. 119, 315-326.

Wagner, K.M., Ruegg, M., Niemann, A., Suter, U., 2009. Targeting and function of the mitochondrial fission factor GDAP1 are dependent on its tail-anchor. PLoS One 4, e5160.

Wai, T., Langer, T., 2016. Mitochondrial dynamics and metabolic regulation. Trends Endocrinol. Metab. 27, 105-117.

Waterham, H.R., Koster, J., Van Roermund, C.W., Mooyer, P.A., Wanders, R.J., Leonard, J.V., 2007. A lethal defect of mitochondrial and peroxisomal fission. N. Engl. J. Med. 356, 1736-1741.

Youle, R.J., Van Der Bliek, A.M., 2012. Mitochondrial fission, fusion, and stress. Science 337, 1062-1065.

Zambelis, T., 2009. Small fiber neuropathy in Charcot-Marie-Tooth disease. Acta Neurol. Belg. 109, 294-297.

Zuchner, S., Mersiyanova, I.V., Muglia, M., Bissar-Tadmouri, N., Rochelle, J., Dadali, E.L., Zappia, M., Nelis, E., Patitucci, A., Senderek, J., Parman, Y., Evgrafov, O., Jonghe, P.D., Takahashi, Y., Tsuji, S., Pericak-Vance, M.A., Quattrone, A., Battaloglu, E., Polyakov, A.V., Timmerman, V., Schroder, J.M., Vance, J.M., 2004. Mutations in the mitochondrial GTPase mitofusin 2 cause Charcot-Marie-Tooth neuropathy type 2A. Nat. Genet. 36, 449-451. 